\title{
Combination of cell signaling molecules can facilitate MYOD1-mediated myogenic transdifferentiation of pig fibroblasts
}

Jinsol Jeong ${ }^{1}$, Kwang-Hwan Choi ${ }^{1,2}$, Seung-Hun Kim¹, Dong-Kyung Lee ${ }^{1,2}$, Jong-Nam Oh', Mingyun Lee ${ }^{1}$, Gyung Cheol Choe ${ }^{1}$ and Chang-Kyu Lee ${ }^{1,3^{*}}$ (D)

\begin{abstract}
Background: Myogenic transdifferentiation can be accomplished through ectopic MYOD1 expression, which is facilitated by various signaling pathways associated with myogenesis. In this study, we attempted to transdifferentiate pig embryonic fibroblasts (PEFs) myogenically into skeletal muscle through overexpression of the pig MYOD1 gene and modulation of the FGF, TGF- $\beta$, WNT, and CAMP signaling pathways.

Results: The MYOD1 overexpression vector was constructed based on comparative sequence analysis, demonstrating that pig MYOD1 has evolutionarily conserved domains across various species. Although forced MYOD1 expression through these vectors triggered the expression of endogenous muscle markers, transdifferentiated muscle cells from fibroblasts were not observed. Therefore, various signaling molecules, including FGF2, SB431542, CHIR99021, and forskolin, along with MYOD1 overexpression were applied to enhance the myogenic reprogramming. The modified conditions led to the derivation of myotubes and activation of muscle markers in PEFs, as determined by qPCR and immunostaining. Notably, a sarcomere-like structure was observed, indicating that terminally differentiated skeletal muscle could be obtained from transdifferentiated cells.

Conclusions: In summary, we established a protocol for reprogramming MYOD1-overexpressing PEFs into the mature skeletal muscle using signaling molecules. Our myogenic reprogramming can be used as a cell source for muscle disease models in regenerative medicine and the production of cultured meat in cellular agriculture.
\end{abstract}

Keywords: MYOD1, Pig, Sequence analysis, Skeletal muscle, Transdifferentiation

\section{Background}

To date, numerous studies have defined various strategies for the differentiation of PSCs (pluripotent stem cells) into specific cell types of ecto-, meso-, and endodermal lineages, which have advantages as infinite cell sources [1-3]. Whereas these directed differentiation

\footnotetext{
* Correspondence: leeck@snu.ac.kr

'Department of Agricultural Biotechnology, Animal Biotechnology Major, and Research Institute of Agriculture and Life Science, Seoul National University, Seoul 08826, South Korea

${ }^{3}$ Institute of Green Bio Science and Technology, Seoul National University, Pyeong Chang, Kangwon-do 25354, South Korea

Full list of author information is available at the end of the article
}

approaches recapitulate in vivo developmental processes through modulation of signaling pathways, they reportedly have defects in terms of time consumption and low efficiency because the small molecules used are also involved in differentiation into other cell types $[4,5]$. For example, the derivation of striated myofibers, a form of mature skeletal muscle, from mouse ESCs (embryonic stem cells) and human iPSCs (induced pluripotent stem cells) reportedly takes 3-4 weeks, albeit with the use of an advanced protocol with a short experimental period $[6,7]$. Therefore, direct reprogramming using the activation of the transcriptional program has been applied to

(c) The Author(s). 2021 Open Access This article is licensed under a Creative Commons Attribution 4.0 International License, which permits use, sharing, adaptation, distribution and reproduction in any medium or format, as long as you give appropriate credit to the original author(s) and the source, provide a link to the Creative Commons licence, and indicate if changes were made. The images or other third party material in this article are included in the article's Creative Commons licence, unless indicated otherwise in a credit line to the material. If material is not included in the article's Creative Commons licence and your intended use is not permitted by statutory regulation or exceeds the permitted use, you will need to obtain permission directly from the copyright holder. To view a copy of this licence, visit http://creativecommons.org/licenses/by/4.0/. The Creative Commons Public Domain Dedication waiver (http://creativecommons.org/publicdomain/zero/1.0/) applies to the data made available in this article, unless otherwise stated in a credit line to the data. 
facilitate the differentiation of PSCs into the desired cell type [5]. However, problems derived from the use of PSCs still remain, including the potential risk of teratoma formation [8] and the requirement of a timeconsuming and fine-tuning process for the derivation and maintenance of the pluripotent state. To overcome the above problems, a transdifferentiation approach is required, in which fully differentiated somatic cells, instead of PSCs, are induced to differentiate directly into target cell types via ectopic expression of transcription factors. Transdifferentiation toward the muscle lineage has been widely studied for a long time since the identification of a master transcription factor in myogenesis, Myod1 [9].

Forced Myod1 expression converts cell fates into muscle, which is responsible for Myod1 functioning as a transcriptional and epigenetic regulator, leading to the activation of muscle-specific genes in a feed-forward manner $[10,11]$. Small molecules can be supplemented in culture conditions for Myod1/MYOD1-overexpressing somatic cells to improve the efficacy of transdifferentiation. The surface of myocytes and the basement membrane of myotubes secrete the FGF2 (fibroblast growth factor 2), which play roles in the activation of muscle stem cells and the expansion of myoblasts, inhibiting terminal differentiation of muscle $[12,13]$. Because the TGF- $\beta$ signaling negatively functions in myogenesis by decreasing Myog activity, inhibitor of TGF type I- $\beta$ receptors, such as SB431542, reportedly enhances the elongation of myotubes through myoblast fusion [13]. In fact, the expression of follistatin, which inhibits the TGF- $\beta$ signaling, is detected in the paraxial mesoderm in vivo [14]. During in vivo myogenesis, the WNT activator secreted from the notochord, neural tube, and surrounding tissue is involved in a series of specifications along with the presomitic mesoderm, somite, dermomyotome, and myotome, as determined by in vitro directed differentiation in human and mouse PSCs [3, 6, 7]. It demonstrates that the WNT signaling induces the commitment of myogenic precursors and has been substantiated by previous research showing that the WNT activator CHIR99021 with SB431542 and FGF2 induces myogenic specification from human iPSCs [14]. In a previous report, the adenylyl cyclase activator forskolin was identified as a myoblast proliferation-promoting factor through CREB-mediated WNT, leading to upregulation of the Pax3, Myf5, and Myod1 genes [15]. The combination of FGF2, a WNT activator, and forskolin stimulated skeletal muscle differentiation in human iPSCs and especially forskolin improved satellite cell expansion in mice [16].

In pigs, myogenic reprogramming could be used as a cell source for the muscle disease modeling and the production of cultured meat. Although, in pig iPSCs, skeletal myotubes were reportedly observed through the activation of WNT signaling and ectopically expressed MYOD1 by overexpression vector and 5-azacytidine (5-aza) [17], the aforementioned limitations derived from iPSCs remain. Moreover, it has been demonstrated that muscle stem cells lose the potential for proliferation and differentiation in long-term culture in vitro [18]. As an alternative, fibroblasts can be obtained in high yield because of their large proportion in the body and are known to be the most effective cell type to accept the expression of Myod1 because they are derived from the mesoderm, which is identical in origin to the muscle [19]. Therefore, in this study, we attempted to transdifferentiate pig fibroblasts into skeletal muscle through overexpression of the pig MYOD1 gene and modulation of the FGF, TGF- $\beta$, WNT, and cAMP signaling pathways.

\section{Methods}

\section{Amino acid sequence analysis}

The MYOD1 amino acid sequences of pig (NP 001002824.1), mouse (NP_034996.2), human (NP_ 002469.2), horse (NP_001304182.1), cow (NP_ 001035568.2), and sheep (NP_001009390.1) were obtained from the NCBI database (https://www.ncbi.nlm. nih.gov/). Comparative analysis of the amino acid sequences was performed using the multiple sequence alignment program MUSCLE (MUltipleby https://www. ebi.ac.uk/Tools/msa/muscle/), and the similarity of proteins from pigs and the other species was analyzed using Protein BLAST (https://blast.ncbi.nlm.nih.gov/).

\section{Construction of inducible $\mathrm{pMYOD1-overexpression} \mathrm{vector}$}

Total RNA was extracted from satellite cells from the biceps femoris of 3-day-old LYD pigs based on our previous study [20], and cDNA was subsequently synthesized. Nested PCR was performed using an outer primer containing 20-bp sequences upstream and downstream of the MYOD1 gene and an inner primer containing the EcoR1 sequence. The following primer set was used: Outer-MYOD1-F, 5' -ATAGAGCAGGGTGGTGGACA3', Outer-MYOD1-R, 5'-CTCAAACTTCTGGGCG CGAG-3', Inner-MYOD1-F, 5'-GAATTCTGGG ATATGGAGCTGCTGTCGC-3', Inner-MYOD1-R, 5' GAATTCTCAGAGCACCTGGTAGATAGGGGTTGG$3^{\prime}$. The PCR product was purified using electrophoresis and inserted into a $\mathrm{T}$ easy vector (Promega, Madison, WI, USA). DNA was extracted from the selected vectors through TA cloning and was sequenced using the following M-13 primer: F, 5'-GTAAAACGACGGCCAG3', R, 5'-CAGGAAACAGCTATGAC-3'. Subsequently, a doxycycline (DOX)-inducible FUW-tetO-pMYOD1 vector was constructed using treatment with the 
restriction enzyme EcoR1 and the FUW-tetO-MCS vector (plasmid \#84008; Addgene, Watertown, MA, USA).

\section{Lentiviral vector production}

Lentiviral vectors were produced as previously described [21]. Briefly, HEK 293 LTV cells (Cell Biolabs, San Diego, CA, USA) were used as the packaging cell line, and five plasmids were used for the production of lentiviral vectors: FUW-tetO-pMYOD1 and FUW-M2rtTA (the transfer plasmid); pLP1 and pLP2 (the packaging plasmids; Invitrogen, Waltham, MA, USA); and pLP/ VSVG (the envelope plasmid; Invitrogen). These plasmids were transfected into HEK 293 LTV cells using the calcium phosphate precipitation method. Subsequently, the LTV culture supernatants were filtered and concentrated. The derived virus pellets were stored at $-76^{\circ} \mathrm{C}$ until use.

\section{Myogenic transdifferentiation of pig fibroblasts}

The pig embryonic fibroblasts (PEFs) isolated in previous study were used [22]. The cells were cultured in Dulbecco's modified Eagle's medium (DMEM; Welgene, Gyeongsan, Korea) supplemented with $10 \%$ fetal bovine serum (FBS; collected and processed in the United States; Genedepot, Katy, TX, USA), 1× GlutaMAX (Gibco, Gaithersburg, MD, USA), $0.1 \mathrm{mmol} / \mathrm{L} \quad \beta$ mercaptoethanol (Gibco), and $1 \times$ antibiotic/antimycotic (Gibco). The exogenous gene was transduced with a lentivirus carrying the FUW-tetO-pMYOD1 or FUWM2rtTA plasmid. The cells were incubated with lentivirus using $8 \mathrm{mg} / \mathrm{mL}$ polybrene (Sigma-Aldrich, St. Louis, MO, USA) for $48 \mathrm{~h}$.
The virus-infected cells were cultured under various conditions, which consisted of basal medium and signaling molecules. The basal medium was composed of DMEM, 10\% FBS, 10\% knockout serum replacement (KSR; Gibco), 10\% 1× GlutaMAX, $0.1 \mathrm{mmol} / \mathrm{L} \quad \beta$ mercaptoethanol, and $1 \times$ antibiotic/antimycotic. The tested signaling molecules were $20 \mathrm{ng} / \mathrm{mL}$ fibroblast growth factor 2 (FGF2; R\&D Systems, Minneapolis, MN, USA), $4 \mu \mathrm{mol} / \mathrm{L}$ TGF- $\beta$ receptor inhibitor SB431542 (Cayman chemical, Ann Arbor, MI, USA), $3 \mu \mathrm{mol} / \mathrm{L}$ GSK3B inhibitor CHIR99021 (Cayman chemical), and $10 \mu \mathrm{mol} / \mathrm{L}$ cAMP activator forskolin (Cayman chemical). $4 \mathrm{ng} / \mathrm{mL}$ DOX was added to activate the inducible vector. In the 'differentiation step', each medium was replaced with a serum-free basal medium containing $2 \%$ horse serum. The media were changed every day, and all cells were cultured under humidified conditions with $5 \%$ $\mathrm{CO}_{2}$ at $37^{\circ} \mathrm{C}$.

\section{Genomic DNA (gDNA) extraction and polymerase chain reaction (PCR)}

Genomic DNA was extracted using the G-spin ${ }^{\text {tu }}$ Total DNA Extraction Kit (iNtRON, Seongnam, Korea). Amplifications were performed using the transgene-specific primers listed in Table 1 and $2 \times$ PCR Master mix solution (iNtRON) containing 5 pmol of each primer set and $50 \mathrm{ng}$ gDNA in a $10-\mu \mathrm{L}$ reaction volume. PCRs were performed in a thermocycler under the following conditions: $94^{\circ} \mathrm{C}$ for $5 \mathrm{~min}$, followed by 35 cycles of denaturation at $95^{\circ} \mathrm{C}$ for $30 \mathrm{~s}$, annealing for $30 \mathrm{~s}$ (annealing temperatures depended on each primer set), and extension at $72{ }^{\circ} \mathrm{C}$ for $30 \mathrm{~s}$, with a final extension at $72{ }^{\circ} \mathrm{C}$ for

Table 1 Primer sets used for PCR and qPCR

\begin{tabular}{|c|c|c|c|c|}
\hline \multirow{2}{*}{$\begin{array}{l}\text { Gene } \\
\text { FUW-TetO-pMYOD1 (ExoMYOD1) }\end{array}$} & \multicolumn{2}{|c|}{ Primer sequence $\left(5^{\prime} \rightarrow 3^{\prime}\right)$} & \multirow{2}{*}{$\begin{array}{l}\text { Annealing temperature, }{ }^{\circ} \mathrm{C} \\
60\end{array}$} & \multirow{2}{*}{$\frac{\text { Product size, bp }}{114}$} \\
\hline & $\mathrm{F}$ & CCAGGTGCTCTGAGAATTCGATA & & \\
\hline & $\mathrm{R}$ & CCACATAGCGTAAAAGGAGCA & & \\
\hline \multirow[t]{2}{*}{ EndoMYOD1 } & $\mathrm{F}$ & AGGGACAGGATAGAGCAGGG & 60 & 199 \\
\hline & $\mathrm{R}$ & TCAAATCTACGTCGCGGAGC & & \\
\hline \multirow[t]{2}{*}{ PAX7 } & $\mathrm{F}$ & GTGCCCTCAGTGAGTTCGAT & 58 & 152 \\
\hline & $\mathrm{R}$ & TCCAGACGGTTCCCTTTGTC & & \\
\hline \multirow[t]{2}{*}{ MYF5 } & $\mathrm{F}$ & AGTTCGGGGACGAGTTTGAG & 60 & 232 \\
\hline & $\mathrm{R}$ & TCAAACGCCTGGTTGACCTT & & \\
\hline \multirow[t]{2}{*}{ MYOG } & $\mathrm{F}$ & GAGCTGTATGAGACATCCCCC & 60 & 75 \\
\hline & $\mathrm{R}$ & GTGGACGGGCAGGTAGTIT & & \\
\hline \multirow[t]{2}{*}{ MHC } & $\mathrm{F}$ & ACAGTGAAGACGGAAGCAGG & 60 & 153 \\
\hline & $R$ & TGCGTAACGCTCTITGAGGT & & \\
\hline \multirow[t]{2}{*}{ рACTB } & $\mathrm{F}$ & CCGGGACCTGACCGACTACC & 60 & 126 \\
\hline & $\mathrm{R}$ & TCGAAGTCCAGGGCGACGTA & & \\
\hline \multirow[t]{2}{*}{ GAPDH } & $\mathrm{F}$ & TGCTCCTCCCCGTTCGAC & 60 & 100 \\
\hline & $\mathrm{R}$ & ATGCGGCCAAATCCGTTC & & \\
\hline
\end{tabular}




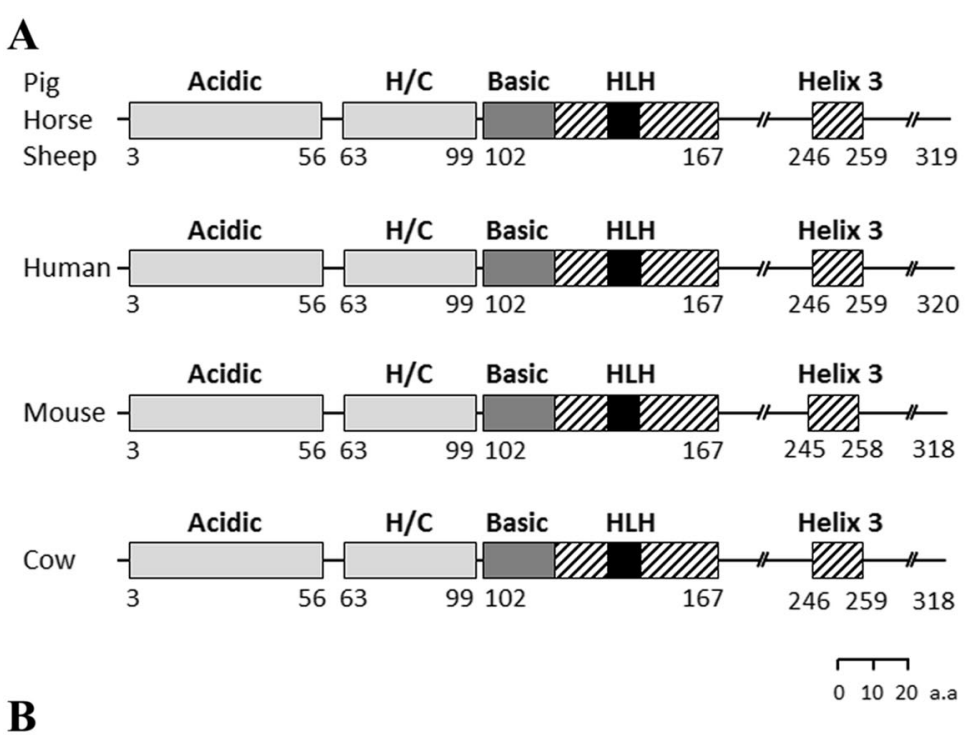

Pig MILLSPLLRDVLITGPDGSLCNFATADDFYDDPCFDSPDLRFFEDLDPRLVHVGAIEKPE Mouse MALLSPLRDIDLTGPDGSLCSFETADDFYDDPCFDSPDLRFFEDLDPRLVHMGAIEKPE Human MLLSPPLRDVDLTAPDGSLCSFATTDDFYDDPCFDSPDLRFFEDLDPRLMHVGAIEKPE Horse MALLSPPLRDVDLSGPDGSLCNFATADDFYDDPCFDSPDLRFFEDLDPRLVHVGAI KKPE Cow MALSPPLRDVDLTGPDGSLCNFATADDFYDDPCFDSPDLRFFEDLDPRLVHVGAI KRE Sheep MfILSPLRDVDITGPDGSLCNFATADDFYDDPCFDSPDLRFEDLDPRLVHVGAI TKPE

Pig EHSHFPAAAHPAPGAREDEHVRAPSGHHQAGRCLIWACKACKRKTTNADRRKAATMRERR Mouse EHAHFPTAVHPGPGAREDEHVRAPSGHHQAGRCLLWACKACKRKTTNADRRKAATMRERR Human EHSHF PAAVHPAPGAREDEHVRAPSGHHQAGRCLLWACKACKRKTTNADRRKAATMRERR Horse EHAHFPATVHPAPGGREDEHVRAPSGHHQAGRCLLWACKACKRKTTNADRRKAATMRERR COW EHSHFPAAAHPAPGAREDEHVRAPSGHHQAGRCLIWACKACKRKTTNADRRKAATMRERR Sheep EHSHFPAAAHPA PGAREDEHVRAPSGHHQAGRCLLWACKACKRKTTNADRRKAATMRERR $* *:: * * *:: . * * . * * . * * * * * * * * * * * * * * * * * * * * * * * * * * * * * * * * * * * * * * * * * * * * *$

Pig RLSKVNEAFETLKRCTSSNPNQRL PKVEILRNAIRYIEGLQALLRDQDAAPPGAAAAFYA Mouse RLSKVNEAFETLKRCTSSNPNQRL PKVEILRNAIRYIEGLQALLRDQDAAPPG-AAAFYA Human RLSKVNEAFETLKRCTSSNPNQRL PKVEILRNAIRYIEGLQALLRDQDAAP PGAAAAFYA Horse RLSKVNEAFETLKRCTSSNPNQRL PKVEILRNAIRYIEGLQALLRDQDAAP PGAAAAFYA COW RLSKVNEAFETLKRCTSSNPNQRL PKVEILRNAIRYIEGLQALLRDQDAAP PGAAAAFYA Sheep RLSKVNEAFETLKRCTSSNPNQRL PKVEILRNAIRYIEGLQALLRDQDAAPPGAAAAFYA $* * * * * * * * * * * * * * * * * * * * * * * * * * * * * * * * * * * * * * * * * * * * * * * * * * * * * * * * * * *$

Pig PGPLPPGRGGEHYSGDSDASSPRSNCSDGMMDYSGPPSGARRRNCYDGTYYSEAPSEPRP Mouse PGPLPPGRGSEHYSGDSDASSPRSNCSDGMMDYSGPPSGPRRONGYDTAYYSEAARESRP Human PGPLPPGRGGEHYSGDSDASSPRSNCSDGMMDYSGPPSGARRRNCYEGAYYNEAPSEPRP Horse PGPLPPGRGGEHYSGDSDASSPRSNCSDGMMDYSGPPSGARRRNCYDGTYYSEAHSEPRP COW PGPLPPGRSGEHYSGDSDASS PRSNCSDGMMDYSGPPSGARRRNCYDRTYYSEAPNEPRP Sheep PGPLPPGRSGEHYSGDSDASSPRSNCSDGMMDYSGPPSGARRRNCYDRAYYSEAPNEPRP PGPLPPGRSGEHYSGDSDASSPRSNCSDGMMDYSGPPSGARRRNCYDRAYYSEAPNEPRP
$* * * * * * * * . . * * * * * * * * * * * * * * * * * * * * * * * * * * * * . * * . * *::: * * . * * * . * *$

Pig GKNAZVSSLDCLSSIVESISTESPAAPALLLADTPRESSPGPQEAAAGSEVE-RGTPTPS Mouse GKSAZVSSLDCLSSIVERISTDSPAAPALLLADAP PESP PGP PEGASLSDTE-QGTQTPS Human GKSAZ VSSLDCLSSIVERISTESPAAPALLLADVPSES P PRRQEAAAPSEGESSGDPTQS Horse GKSAZVSSLDCLSSIVERISTESPAAPALLLADAPPESSPGPQETATPSEGE-RGAPTPS COW GKSAZVSSLDCLSSIVERISTESPAAPALLLADAPPESSPGPQE-AAGSEVE-RGTPAPS Sheep GKSAZVSSLDCLSSIVERISTESPAAPALLLADAPPESSPGPQEAAAGSEVE-CGTPAPS $* * . * * * * * * * * * * * * * * * *: * * * * * * * * * * * * * * . * * *: * * * * *: *$

Pig PDAAPQCPASANPNPIYQVI

Mouse PDAAPQCPAGSNPNAIYQVI

Human PDAAPQCPAGANPNPIYQVI

Horse PDAAALCPAGANPNPIYQVI

COW PDTAPQGLAGANPNPIYQVI

Sheep PDTAPQGLAGANPNPIYQVI

**:*..*.:***,*****

Fig. 1 (See legend on next page.) 
(See figure on previous page.)

Fig. 1 MYOD1 amino acid sequence analysis. The MYOD1 amino acid sequences of the pig (NP_001002824.1), mouse (NP_034996.2), human (NP_002469.2), horse (NP_001304182.1), cow (NP_001035568.2), and sheep (NP_001009390.1) were acquired from the NCBI database. a Schematic representation of the MYOD1 protein. The whole protein (black line) and its acidic and H/C domains (light gray boxes), basic domain (dark gray box), helix motifs (slashed boxes), and loop motif (black box) are indicated. The diagram is scaled. b Alignment and comparison of the MYOD1 amino acid sequence via the multiple sequence alignment program MUSCLE. The acidic domain (black line), H/C domain (light gray line), basic domain (gray box), helix1 (red box) -loop (blue box) -helix2 (green box), and helix3 motif (dark gray line) are indicated in the amino acid alignment. Arg ${ }^{111}$ and $\mathrm{Ala}^{114}-\mathrm{Thr}^{115}$ are marked in red. The consensus sequence of amino acids among the species is described with an asterisk at the bottom line

$7 \mathrm{~min}$. The amplified PCR products were visualized using electrophoresis on a $1 \%$ agarose gel stained with ethidium bromide.

\section{Immunocytochemistry (ICC) analysis}

Before staining, all cell samples were preincubated for 5 min at $4{ }^{\circ} \mathrm{C}$ and fixed with $4 \%$ paraformaldehyde for $15 \mathrm{~min}$. After washing twice with Dulbecco's phosphatebuffered saline (DPBS; Welgene), the samples were treated for $1 \mathrm{~h}$ with $10 \%$ goat serum in DPBS to prevent nonspecific binding. Serum-treated cells were incubated overnight at $4{ }^{\circ} \mathrm{C}$ with primary antibodies. The primary antibodies used were as follows: rabbit anti-MYOD1 (1:100, Thermo Fisher, Waltham, MA, USA; PA5-23078) and mouse anti-MHC (1:50, Sigma-Aldrich; 05-716). When antibodies against MYOD1 were applied, fixed cells were treated for $15 \mathrm{~min}$ with $0.2 \%$ Triton-X100 (Sigma-Aldrich) before serum blocking. After incubation with the primary antibody, the cells were treated for $2 \mathrm{~h}$ at room temperature with an Alexa Fluor-conjugated secondary antibody. Nuclei were stained with Hoechst 33342 (Molecular Probes, Eugene, OR, USA). Images of stained cells were captured using a TE2000-U inverted microscope (Nikon, Tokyo, Japan).

\section{Quantitative real-time polymerase chain reaction ( $q P C R$ )} Total RNA was extracted from the cells using TRIzol ${ }^{\circledR}$ Reagent (Invitrogen) according to the manufacturer's instructions. cDNA was synthesized using the High Capacity RNA-to-cDNA Kit (Applied Biosystems, Waltham,

Table 2 Similarity analysis of the pig MYOD1 amino acid sequence compared to other species

\begin{tabular}{llllll}
\hline & \multicolumn{5}{c}{ Similarity between pig and the other species, \% } \\
\cline { 2 - 6 } & Mouse & Human & Horse & Cow & Sheep \\
\hline MYOD1 protein & 89.03 & 93.12 & 94.36 & 95.92 & 95.61 \\
Acidic & 92.59 & 92.59 & 98.15 & 100.00 & 100.00 \\
H/C & 89.19 & 97.30 & 89.19 & 100.00 & 100.00 \\
bHLH & 100.00 & 100.00 & 100.00 & 100.00 & 100.00 \\
Helix3 & 92.86 & 92.86 & 92.86 & 92.86 & 92.86 \\
\hline
\end{tabular}

Similarity comparison between pig and the other species was confirmed on the score via the Protein BLAST program
MA, USA), producing a final volume of $20 \mu \mathrm{L}$. The derived cDNA samples were amplified with PowerSYBR ${ }^{\circledR}$ Green PCR Master Mix (Applied Biosystems) containing 0.5 pmol of each primer set listed in Table 1 in a $10-\mu \mathrm{L}$ reaction volume. Amplification and detection were conducted using the ABI 7300 Real-Time PCR system (Applied Biosystems) under the following conditions: one cycle of $50{ }^{\circ} \mathrm{C}$ for $2 \mathrm{~min}$ and $95^{\circ} \mathrm{C}$ for $10 \mathrm{~min}$, followed by 40 or 45 cycles of denaturation at $95^{\circ} \mathrm{C}$ for $15 \mathrm{~s}$ and annealing/extension for $1 \mathrm{~min}$ (annealing/extension temperatures depended on each primer set). The relative expression level was calculated by normalizing the threshold cycle $(\mathrm{Ct})$ values of each gene to that of GAPDH via the $\Delta-C$ t method [23].

\section{Statistical analysis}

The data from the qPCR analyses are presented as the mean \pm standard error of the mean (SEM) and were analyzed using Prism 6 software (GraphPad Software; San Diego, CA, USA). The significance of differences was determined by one-way analyses of variance followed by Fisher's least significant difference test. Differences were considered significant at $P<0.05$.

\section{Results}

\section{Pig MYOD1 overexpression vector construction}

Myod1/MYOD1 is reportedly identified as a master transcription factor in myogenesis, thereby inducing myogenic transdifferentiation in non-muscle cells $[9$, 24-27]. Thus, a comparative MYOD1 sequence analysis was performed among various species to assess whether pig MYOD1 contains functionally conserved sequences for myogenesis, as in the other species, before vector construction for ectopic pig MYOD1 (pMYOD1) expression. The pig MYOD1 whole protein has a similar size to MYOD1 protein in other species (Fig. 1A). To all the analyzed species, including pig, the MYOD1 protein contains acidic domains, histidine and cysteine-rich $(\mathrm{H} /$ C) domains, basic-helix1-loop-helix2 (bHLH) domains, and helix3 domains [28, 29]. Subsequently, the MYOD1 sequences from those species were aligned, and the similarity score was assessed at the amino acid level (Fig. 1b and Table 2). In the bHLH domain, Ala ${ }^{114}-\mathrm{Thr}^{115}$ and $\mathrm{Arg}^{111}$ reportedly endow the MYOD1 protein with 


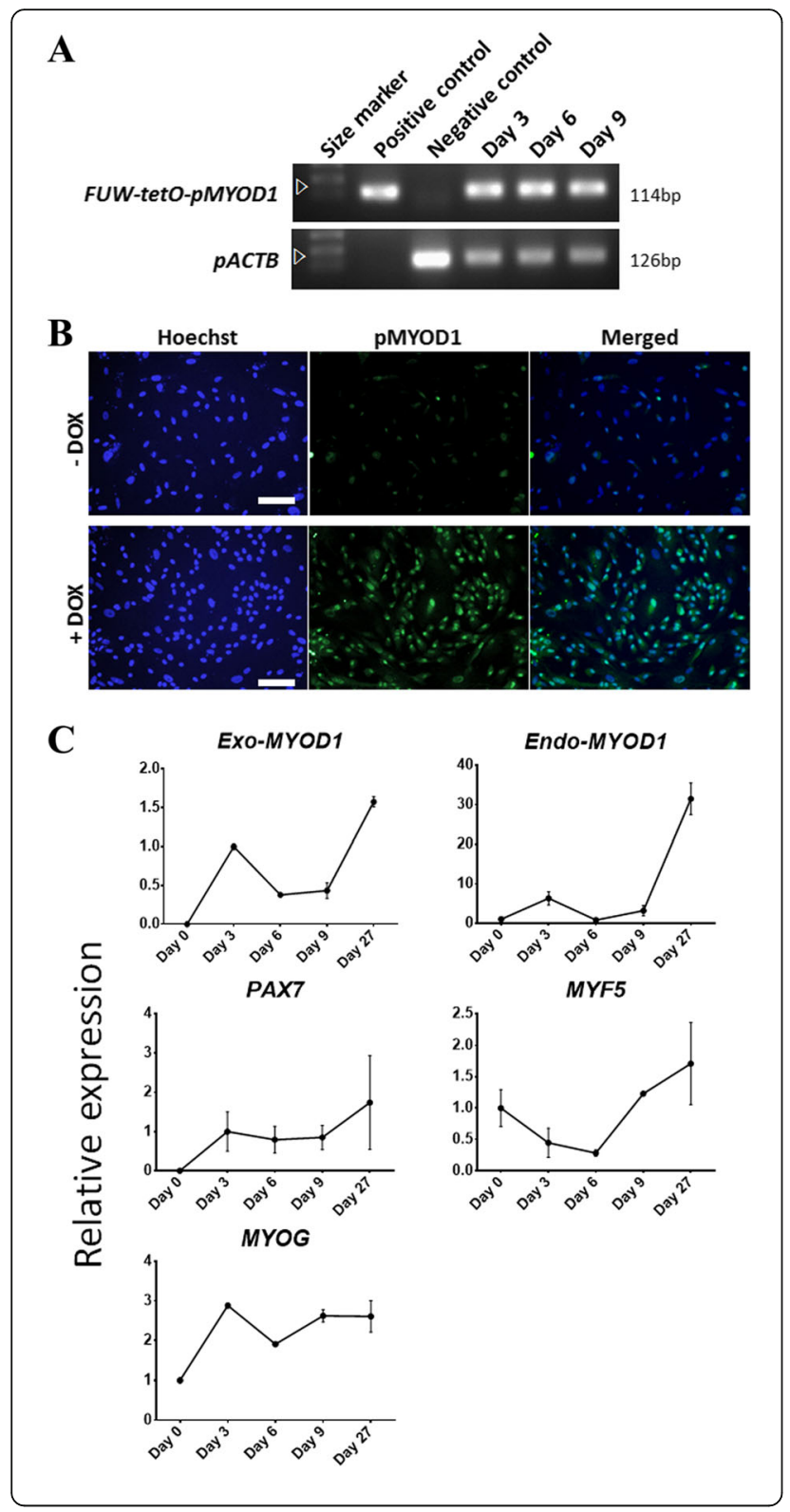

Fig. 2 Vector construction and validation using transfection into PEFs. Construction of an inducible vector (FUW-tetO-pMYOD1) carrying the MYOD1 gene isolated from satellite cells in 3-day-old LYD biceps femoris. Cells were cultured in a serum-free basal medium containing $2 \%$ horse serum and $4 \mathrm{ng} / \mathrm{mL}$ doxycycline (DOX). a PCR results using genomic DNA (gDNA) from PEFs transfected with FUW-tetO-pMYOD1 to confirm the integration of the exogenous PMYOD1 gene. Cells were sampled on days 3, 6, and 9 of DOX treatment. The FUW-tetO-pMYOD 1 plasmid was a positive control, and PEFs without transfection were the negative control. The arrows indicate the FUW-tetO-pMYOD1 plasmid vector and loading control PACTB (porcine beta-actin; internal protein). b Immunofluorescence images for PMYOD1 in PEFs transfected with FUW-tetO-pMYOD1. Scale bar $=100 \mu \mathrm{m}$. c qPCR results of PEFs transfected with the FUW-tetO-pMYOD1 vector to confirm the expression patterns of muscle-associated genes (EXO-MYOD1, EndoMYOD1, PAX7, MYF5, and MYOG). Cells on day 0 were used as a negative control. Relative gene expression is represented as a trend line, describing 1 as the value of day 0 in Endo-MYOD1, MYF5, and MYOG and the value of day 3 in EXO-MYOD1 and PAX7

myogenic activity [30, 31]. In fact, these residues (marked in red; Fig. 1b) were confirmed to be conserved in the basic region of all the analyzed species. It is noteworthy that the bHLH domain showed a $100.00 \%$ similarity between pig and all other species. Altogether, porcine MYOD1, especially the bHLH domain, was identified as an evolutionarily conserved protein, which seems that its role is also conserved in myogenesis across species.

Based on the above analyses, doxycycline (DOX)-inducible $\mathrm{p} M Y O D 1$ overexpression vectors were generated including the MYOD1 gene isolated from satellite cells in 3-day-old LYD biceps femoris. To verify the function of these constructed vectors, they were introduced into pig embryonic fibroblasts (PEFs) through lentiviral infection for stable transgene expression $[4,27]$. First, the integration of the exogenous $\mathrm{p} M Y O D 1$ gene was confirmed by PCR targeting the FUW-tetO-pMYOD1 sequence in gDNA of PEFs infected with a lentivirus carrying the vectors (pMYOD1-PEFs) (Fig. 2a). At day 9, the gene of interest had been inserted stably into the genome of PEFs. Then, MYOD1 expression was confirmed at the protein level using immunostaining in pMYOD1-PEFs (Fig. 2b). The vectors were activated by the addition of DOX, leading to ectopic MYOD1 expression. Finally, the expression pattern of muscle-associated genes (Exo-MYOD1, Endo-MYOD1, PAX7, MYF5, and $M Y O G)$ was analyzed in $\mathrm{p} M Y O D 1-\mathrm{PEFs}$ using $\mathrm{qPCR}$ (Fig. 2c). These genes have been characterized as myogenic lineage-specific markers, such as skeletal muscle progenitor/myoblasts (PAX7, MYF5, and MYOD1) and myocytes (MYOD1 and MYOG) [3]. Exo-MYOD1 overexpression by vector activation increased the expression of endogenous muscle-associated genes. During extended cell culture, the expression of these genes was 


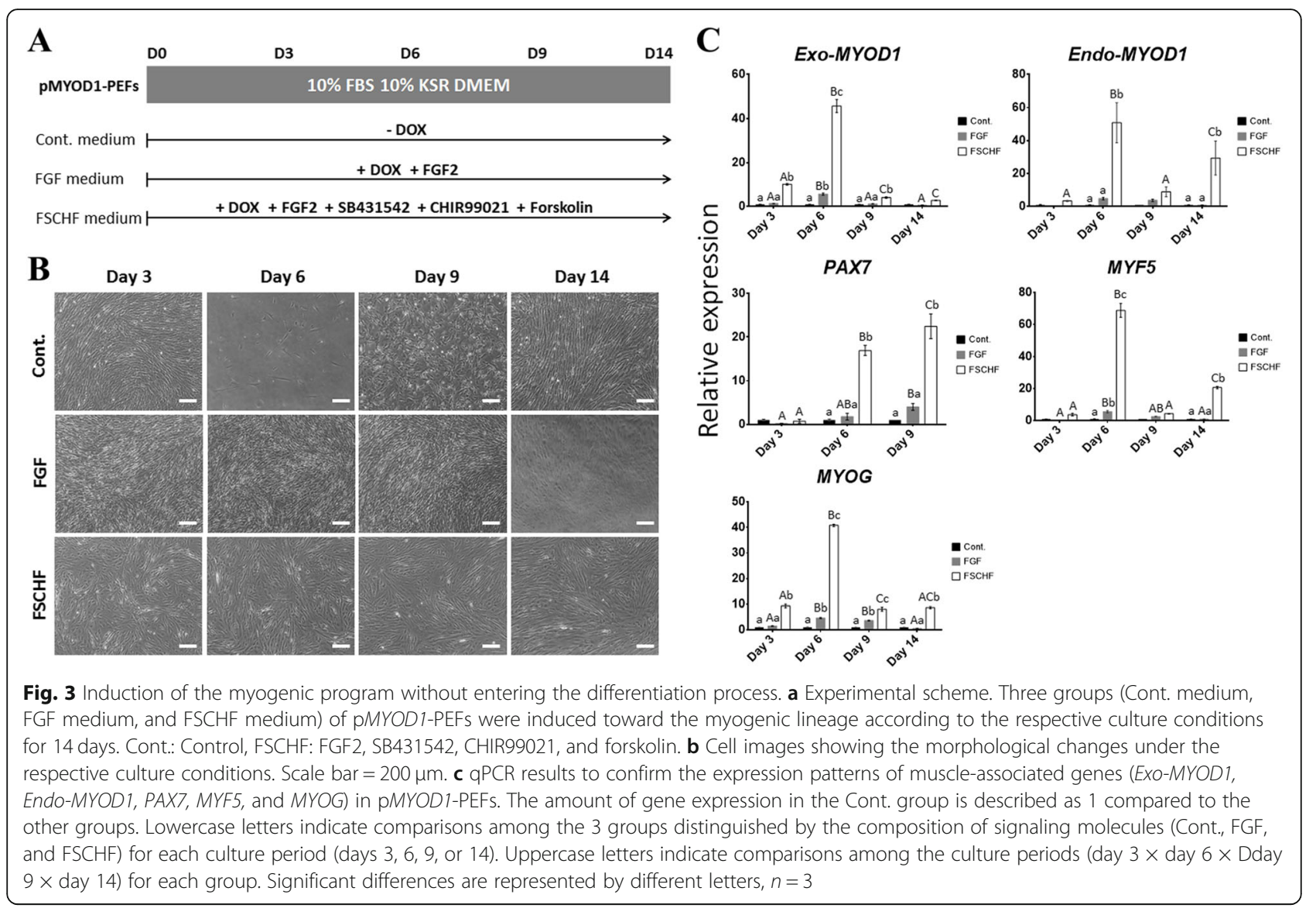

stably maintained. In conclusion, we constructed a DOX-inducible $\mathrm{p} M Y O D 1$ overexpression vector that triggered the expression of muscle markers in long-term culture, indicating its stable function.

\section{Myogenic transdifferentiation of PEFs through overexpression of MYOD1 and cell signaling modulation} The expression of endogenous muscle markers, including Endo-MYOD1, was enhanced via ectopic MYOD1 expression, as shown in Fig. 2c. However, because of the mild changes in each gene, transdifferentiated muscle cells from fibroblasts were not observed. It has been shown that complete transdifferentiation is achieved by genetic modulation along with suitable culture conditions for specific cell types [32], suggesting that optimization of culture conditions is required. According to previous studies, a 2-step transdifferentiation protocol was employed with some modification to derive myogenic cells through MYOD1 overexpression [8, 17, 33]. In the 'induction' step, the myogenic program was activated with the stimulation of transcription factors associated with myogenesis, thereby leading to the commitment into a myogenic lineage. Briefly, pMYOD1PEFs were treated with various signaling molecules, such as FGF2, SB431542, CHIR99021, and forskolin, which are involved in the regulation of myogenesis $[8,14]$. Then, transdifferentiation was promoted through serum starvation in the 'differentiation' step.

To ensure efficient myogenic conversion, we investigated the transition point where exogenous MYOD1 leads to the peak expression of endogenous skeletal muscle-specific genes. In addition, $\mathrm{p} M Y O D 1-\mathrm{PEFs}$ were cultured in mitogen-rich media in which myogenic induction was sustained without entering the differentiation process (Fig. 3a). While the FSCHF group had a long cylindrical shape due to elongation of the cytoplasm, a typical fibroblastic and round shape was observed in the control and FGF groups, respectively (Fig. 3b). The alteration in the FSCHF group was maintained by the end of the culture period, resulting in a similar morphology to myoblasts, as previously reported $[17,34]$. The myogenic genes were upregulated by forced MYOD1 expression (Fig. 3c). Compared to other groups, the relative gene expression of the FSCHF group was higher across all the genes and culture periods. These results suggested that the Exo-MYOD1 effect was enhanced by the combination of four signaling molecules rather than DOX-induced exogenous $M Y O D 1$ per se or additional FGF2. While the gene expression of the FGF group was gradually changed, that of the FSCHF 

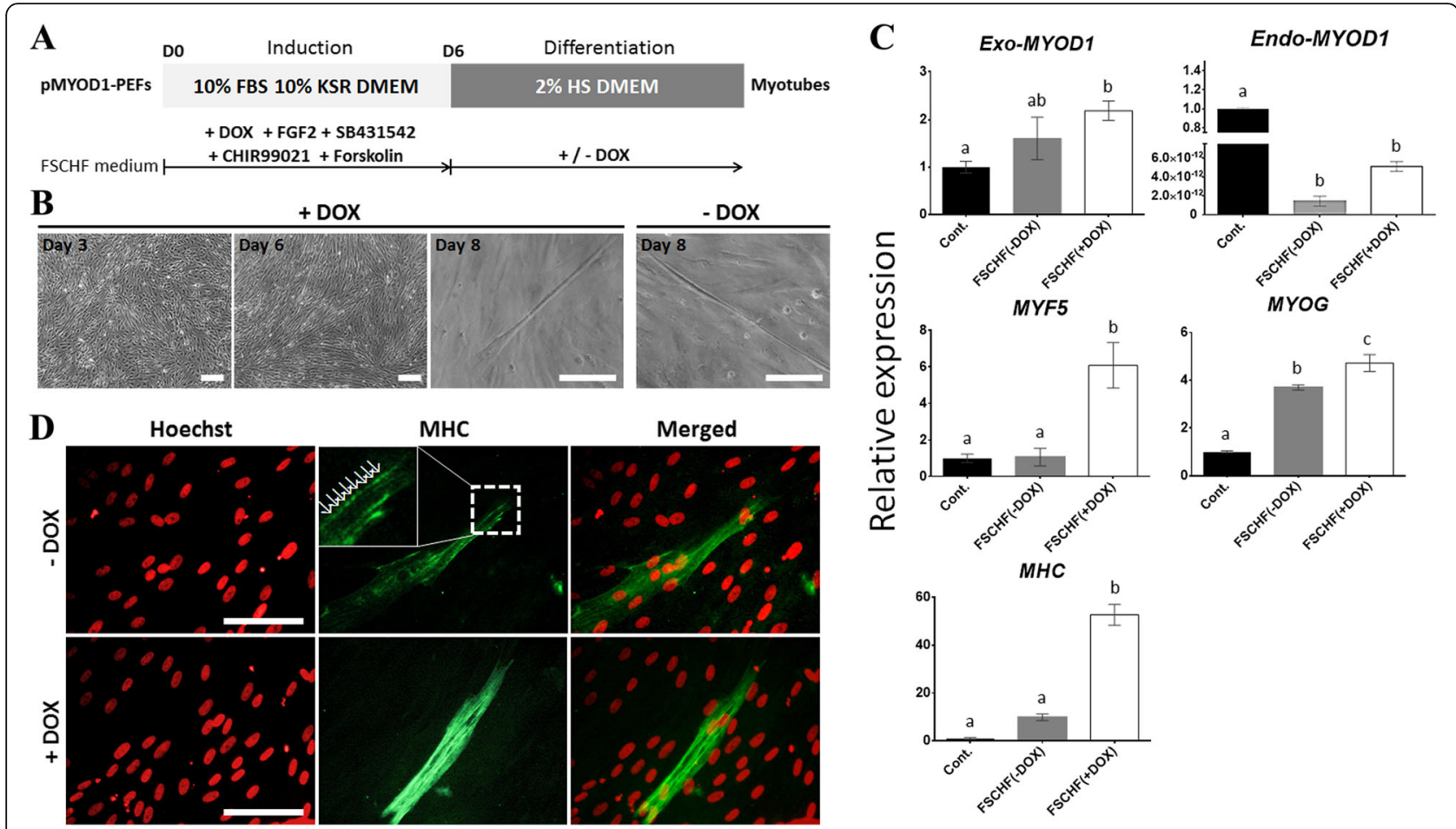

Fig. 4 Transdifferentiation of PMYOD1-PEFs into myotubes using signaling molecules. a Experimental design for the transdifferentiation of PMYOD1-PEFs into myocytes. The PMYOD1-PEFs were induced toward the myogenic program in the 'induction' step, and the induced cells were promoted for myogenic reprogramming in the 'differentiation' step. In the differentiation stage, one group was treated with DOX, and the other was not. HS: horse serum, Cont:: Control, FSCHF: FGF2, SB431542, CHIR99021, and forskolin. b Cell images under culture conditions with or without DOX. Scale bar $=200 \mu \mathrm{m}$. c qPCR results to confirm the expression patterns of muscle-associated genes (Exo-MYOD1, Endo-MYOD1, MYF5, MYOG, and MHC) in PMYOD1-PEFs. The Cont. group contained PMYOD1-PEFs cultured in basal media. The amount of gene expression in the Cont. group is described as 1 compared to the other groups. Significant differences are represented by different letters, $n=3$. $\mathbf{d}$ Immunofluorescence images for MHC of pMYOD1-PEFs. The arrows marked a sarcomere-like structure. Scale bar $=100 \mu \mathrm{m}$

group was significantly increased on day 6 and then decreased. The aforementioned expression patterns were observed in all the markers except $P A X 7$, which was upregulated up to day 9 in both groups. Taken together, pMYOD1-PEFs treated with a cocktail of FGF2, SB431542, CHIR99021, and forskolin for 6 days were used for further experiments.

Based on the above observations, we established a myogenic transdifferentiation protocol in which the FSCHF medium for induction into a myogenic lineage was replaced with a low-serum medium for the initiation of differentiation on day 6 (Fig. 4a). The replaced culture condition was classified into two groups distinguished by the addition of DOX (+DOX and -DOX) to assess whether consistent activation of the myogenic program could enhance transdifferentiation. Notably, multinucleated myotubes via fusion of myoblasts were observed on day 8 in both groups (Fig. 4b). According to the qPCR analyses performed with a sample from day 9, transcripts of the Exo-MYOD1, MYF5, MYOG, and Myosin heavy chain (MHC) genes were upregulated in the +/- DOX groups (Fig. 4c). Unlike that of the other genes, gene expression of EndoMYOD1 was significantly decreased in the +/- DOX group. Across all of the genes, especially MYF5 and $M H C$, the +DOX group showed significantly higher expression levels than the -DOX group, demonstrating that continuous MYOD1 overexpression during the differentiation step facilitates myogenic transdifferentiation. The expression of MHC, a marker of late differentiation in myogenesis, was detected in the day 9 sample by immunofluorescence analysis (Fig. 4d). Interestingly, a sarcomere-like structure with a striated pattern was observed, as previously reported [35], indicating that the mature myotube could be assembled. Unless the MYOD1 was ectopically expressed, the FSCHF cocktail was insufficient to trigger the activation of myogenesis-related genes in PEFs, indicating that the MYOD1 plays a crucial role in determining the myogenic cell fate during transdifferentiation of the pig fibroblasts (Fig. 5). Therefore, the established protocol using ectopic MYOD1 expression and signaling molecules associated with myogenesis, such as FGF2, a TGF- $\beta$ inhibitor, a WNT 


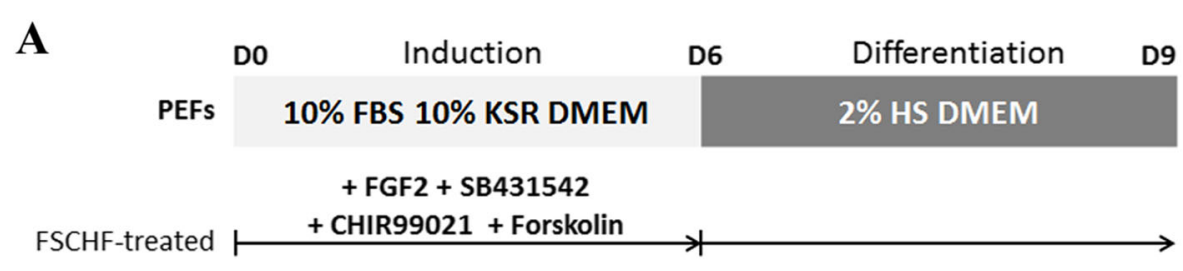

B

Non-treated

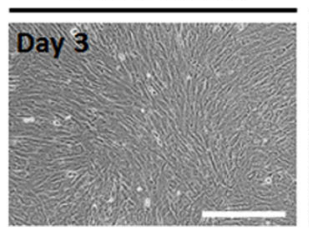

FSCHF-treated

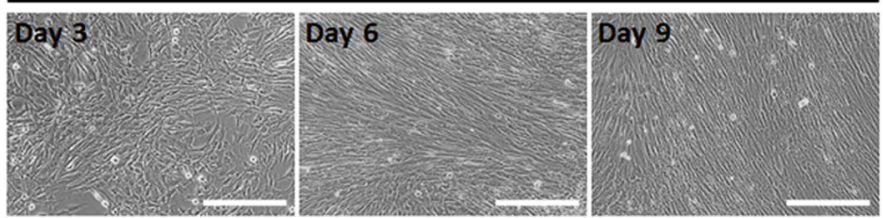

PAX7

C

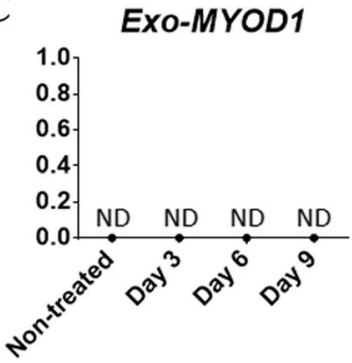

MYF5

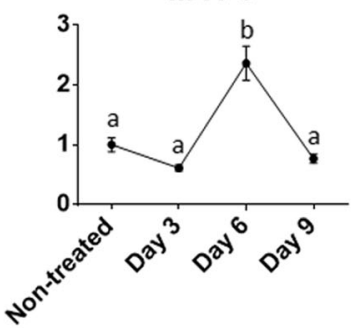

Endo-MYOD1

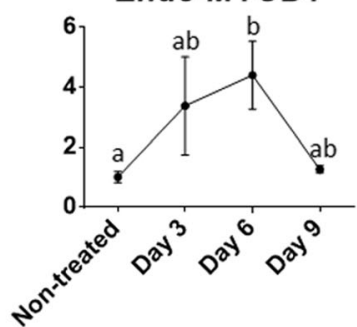

MYOG

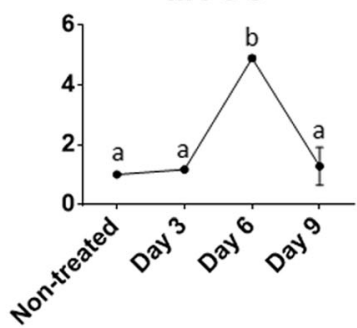

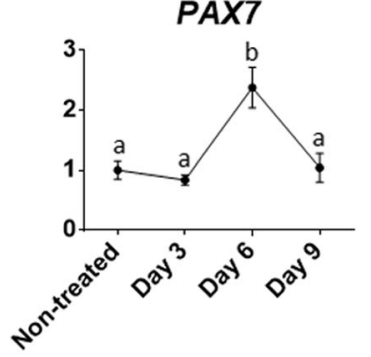

MHC

Fig. 5 Treatment of signaling molecules without MYOD1 overexpression in PEFs. a Experimental design. PEFs were cultured in the medium containing the FSCHF cocktail and the medium was replaced with a medium containing $2 \%$ horse serum without signaling molecules on day 6. The non-treated group contained PEFs which was cultured in basal media. $\mathbf{b}$ Cell images under respective culture conditions. Scale bar $=200 \mu$ m. c qPCR results to confirm the expression patterns of muscle-associated genes (EXO-MYOD1, Endo-MYOD1, PAX7, MYF5, MYOG, and MHC) in PEFs. The amount of gene expression in the non-treated group is described as 1 compared to the other groups. Significant differences are represented by different letters, $n=3$

activator, and a cAMP activator, enabled fibroblasts to be reprogrammed into skeletal muscle.

\section{Discussion}

Pig MYOD1 has an evolutionarily conserved bHLH domain that regulates myogenesis

Previously, numerous attempts have been made to reprogram non-muscle cells into skeletal muscle by modulating the expression of the transcription factor Myod1, which plays an important role in myogenesis [10, 11]. 5-azacytidine (5-aza), a DNA methyltransferase inhibitor, induces demethylation of the Myod1 locus in differentiated somatic cells and increases Myod 1 transcripts, leading to transdifferentiation into the myogenic lineage [9,
36]. However, 5-aza does not target site-specific demethylation; it induces genome-wide demethylation because 5-aza is incorporated into genomic DNA as a competitive analog of cytosine and then disintegrates DNA methyltransferase by trapping [37]. In fact, when fibroblasts were treated with 5-aza, adipocytes and chondrocytes were also observed [38]. Additionally, it has been substantiated that 5 -aza exhibits cytotoxicity by causing DNA double-strand breaks and apoptosis [39]. Thus, myogenic transdifferentiation using 5-aza is inappropriate in terms of safety and efficiency. As an alternative strategy, forced Myod1/MYOD1 expression without induction by 5 -aza has been used to activate the myogenic program in human and mouse fibroblasts [27, 34, 40]. In 
pig, myotubes were differentiated from induced pluripotent stem cells (iPSCs) via a combination of a 5-aza treatment and ectopically expressed MYOD1 [17]. Although contractile porcine myotubes with sarcomeres were obtained from iPSCs within 11 days, the entire process would be more time-consuming because of the iPSC derivation period. Here, we established a direct transdifferentiation protocol with pig fibroblasts for the generation of skeletal muscle using porcine $M Y O D 1$ overexpression and myogenesis-associated signaling molecules, bypassing the induction of the pluripotent state.

Comparative analysis of the MYOD1 amino acid sequence showed that the bHLH domain in MYOD1 was thoroughly conserved across various species. A previous study suggested that conserved sites are less permissive to evolutionary mutation due to their functional or structural importance [41]. This finding indicates that the bHLH domain is an essential part of the MYOD1 protein, the function of which is associated with myogenesis, as in other species [34, 42]. The basic region in the bHLH domain of Myod1 recognizes and binds the E-box, which is a conserved DNA sequence that is frequently distributed throughout the genome rather than specifically located in the regulatory region of myogenic genes [42]. The myogenic specificity of Myod1 is derived from $\mathrm{Ala}^{114}-\mathrm{Thr}^{115}$ in the basic region $[29,43]$. In fact, it has been verified that Myod1 binds to both canonical and noncanonical E-boxes [10]. These myogenic codes direct Myod1 to bind to noncanonical E-boxes of Myog, one of the Myod1 target loci, and to interact with Pbx/ Meis cofactors associated with myogenic genes [30]. In particular, $\mathrm{Ala}^{114}$ leads to an appropriate conformational change allowing myogenic activity by mediating the contact of $\mathrm{Arg}^{111}$ and guanine in DNA [31]. In addition to the basic region, the HLH motif of Myod1 is also required for myogenesis because the HLH motif dimerizes with other bHLH proteins, whose basic domains are involved in E-box binding [42]. The other domains are also highly conserved and have been known to be functional Myod1 domains [11, 44]. For example, the acidic domain acts as a transcriptional activation domain (TAD) through additional DNA binding near E boxes, and both the $\mathrm{H} / \mathrm{C}$ and helix3 domains are involved in chromatin remodeling to allow active transcription of sequential myogenic genes. Accordingly, pig MYOD1 is capable of muscle-specific gene expression through conserved domains, especially the bHLH motif, preventing differentiation into non-muscle cell fate.

\section{Myogenic transdifferentiation is enhanced by activation of the FGF, WNT, and CAMP signaling pathways and inhibition of the TGF- $\beta$ signaling pathway}

Doxycycline (DOX)-inducible pMYOD1 overexpression vectors were produced with the conserved pig MYOD1 sequence, as described above. Because differentiation is blocked when proliferation is enhanced by mitogen in serum, a low concentration of horse serum has been widely employed for myogenic differentiation in humans and mice [45-47]. However, transdifferentiated muscle cells were not observed when the aforementioned conventional culture conditions were applied. This result was consistent with the qPCR data that showed mild upregulation of endogenous muscle genes (Fig. 2c). It was surmised that myogenic reprogramming in pigs requires more supportive culture conditions than in mice and humans. For these reasons, a mixture of small molecules, such as FGF2, a TGF- $\beta$ inhibitor (SB431542), a WNT activator (CHIR99021), and a cAMP activator (forskolin), was selected to facilitate the conversion of cell fate into the myogenic lineage, as applied in previous research [8]. While activation of the FGF, WNT, and cAMP signaling pathways is required for specification into the myogenic lineage and proliferation of committed myoblasts, inhibition of the TGF- $\beta$ signaling pathway is involved in myotube formation $[3,13,15]$. These signaling molecules, except forskolin, are secreted during myogenesis in vivo, thus recapitulating the endogenous signaling pathway for muscle formation and regeneration. Forskolin has been reported to be involved in skeletal muscle differentiation from human iPSCs and to improve satellite cell expansion in mice [16]. Supporting the function of forskolin, our preliminary study showed that the removal of forskolin failed myogenic transdifferentiation (data not shown).

With the treatment of these four signaling molecules, endogenous myogenic genes were highly triggered by exogenous MYOD1 (Exo-MYOD1) (Fig. 3c). Consistent with these observations, it has been demonstrated that ectopically expressed $M Y O D 1$ upregulates endogenous MYOD1 (Endo-MYOD1), PAX7, MYF5, and MYOG, which reinforces the notion that $M Y O D 1$ is a key regulator in myogenesis. Exo-MYOD1 increased Endo-MYOD1 via an autoregulatory loop, as previously reported [26]. The temporal expression of myogenic genes has a hierarchy with stage-specific markers: $P A X 7$ in myogenic progenitor cells and MYF5 and MYOD1 in committed myogenic cells, followed by $M Y O G$ in the differentiation phase $[3,48]$. In the present study, after day 9 from the Dox treatment, the expression of Endo-MYOD1 and $M Y F 5$ was increased while that of $P A X 7$ was undetected, which indicates the $P A X 7$ was involved in the early myogenic-transdifferentiation followed by the activation of the MYOD1 and MYF5 in the subsequent phase as like in vivo myogenesis. Chromatin immunoprecipitation reportedly showed that mesoderm or myoblast markers, including Pax7/PAX7 and Myog/MYOG, were directly activated by Exo-Myod1, leading to an increase in Myf5 [27, 49]. Because MYF5 is upstream of MYOD1, it was 
reported that MYF5 was not expressed in MYOD1-overexpressing human iPSCs [33]. However, when treated with signaling molecules, forced Myod1 expression converted mouse fibroblasts into Pax7- and Myf5-positive myogenic progenitor cells [8]. Taken together, various cell types that belong to the myogenic lineage can be derived in mitogen-rich media. In the $\mathrm{C} 2 \mathrm{C} 12$ myoblast cell line, mitogen-rich culture conditions stimulated myoblast growth without differentiation, whereas skeletal muscle was differentiated with the expression of differentiation-specific genes under low-mitogen culture conditions [50]. For the enrichment of terminally differentiated myotubes, the culture conditions were switched, and a medium containing $2 \%$ horse serum without signaling molecules on day 6 was used, in which endogenous muscle genes peaked by Exo-MYOD1.

As shown in the applied protocol presented in Fig. 4a, multinucleated and elongated myotubes were observed. These myotubes were formed through the fusion of mononucleated myoblasts exiting from the cell cycle, followed by a reorganization of the cytoskeleton [3]. Based on the higher expression of muscle genes in the +DOX group, continuous MYOD1 overexpression seems to enhance myogenic conversion in a feed-forward mechanism [42]. Myotubes and myofiber express myosin heavy chain (MHC) [6], which is a downstream gene of Myod1 [26]. MHC provides contractility to eukaryotic cells through filament assembly in the form of striated sarcomeres, such as skeletal and cardiac muscle [51]. In fact, the expression of $M H C$ was increased at the RNA level and a sarcomere-like structure was detected by immunostaining for MHC proteins in accordance with previous research [35]. Altogether, our protocol enables the transdifferentiated muscle to undergo terminal differentiation and maturation into skeletal muscle.

\section{Conclusions}

In summary, fully differentiated somatic cells of pigs can be reprogrammed into mature skeletal muscle by the pig MYOD1 gene. Modulation of the FGF, TGF- $\beta$, WNT, and cAMP signaling pathways is required for the cell fate conversion into the myogenic lineage. The transdifferentiated muscle expressed skeletal muscle markers and had the structure of a striated sarcomere, implying that these matured myotubes possess a contractile capacity. Given the role of pig as significant livestock for supplying meat, the myogenic reprogramming of pig cells can be applied to increase agricultural yield and produce cultured meat. Additionally, pigs provide biomedical applications in preclinical studies for human disease because of their anatomical and physiological similarities with humans $[52,53]$. For example, transdifferentiated pig muscle cells can offer a cell source for skeletal muscle disease modeling and drug screening in regenerative medicine. Finally, this study provides fundamental knowledge for the developmental biology in revealing the genetic network and signaling pathways underlying myogenesis.

\section{Abbreviations \\ a.a: Amino acid; 5-aza: 5-Azacytidine; bHLH: Basic-helix1-loop-helix2; Cont:: Control; DOX: Doxycycline; Endo-MYOD1: Endogenous MYOD1; ESCs: Embryonic stem cells; EXo-MYOD1: Exogenous MYOD1; FBS: Fetal bovine serum; FGF2: Fibroblast growth factor 2; FSCHF: FGF2, SB431542, CHIR99021, and forskolin; gDNA: Genomic DNA; H/C: Histidine and cysteine- rich; ICC: Immunocytochemistry; iPSCs: Induced pluripotent stem cells; KSR: Knockout serum replacement; MHC: Myosin heavy chain; PACTB: Porcine beta-actin; PEFs: Pig embryonic fibroblasts; pMYOD1: Pig MYOD1; pMYOD1- PEFs: PEFs infected with a lentivirus carrying the PMYOD1 gene; \\ PSCs: Pluripotent stem cells; qPCR: Quantitative real-time polymerase chain reaction; TAD: Transcriptional activation domain}

\section{Acknowledgments}

Not applicable.

\section{Authors' contributions}

J. Jeong, K.H. Choi, S.H. Kim, D.K. Lee, J.N. Oh, M. Lee, GC. Choe and C.K. Lee designed research. J. Jeong and K.H. Choi performed, analyzed, and interpreted all experiments. J. Jeong and C.K. Lee wrote the paper. C.K. Lee finally approved the manuscript.

Funding

This work was supported by the BK21 Four program, the Korea Evaluation Institute of Industrial Technology (KEIT; 20012411), and the National Research Foundation of Korea (NRF) grant (2021R1A2C4001837).

Availability of data and materials

Not applicable.

\section{Declarations}

Ethics approval and consent to participate

The care and experimental use of pigs were approved by the Institutional Animal Care and Use Committee (IACUC) at Seoul National University (approval nos.: SNU-140328-2 for pig fetal fibroblast isolation).

Consent for publication

Not applicable.

Competing interests

No potential conflicts of interest relevant to this article are reported.

\section{Author details}

${ }^{1}$ Department of Agricultural Biotechnology, Animal Biotechnology Major, and Research Institute of Agriculture and Life Science, Seoul National University, Seoul 08826, South Korea. ${ }^{2}$ Present address: Research and Development Center, Space F corporation, Hwasung-si, Gyeonggi-do 18471, South Korea. ${ }^{3}$ Institute of Green Bio Science and Technology, Seoul National University, Pyeong Chang, Kangwon-do 25354, South Korea.

Received: 3 November 2020 Accepted: 11 March 2021

Published online: 13 May 2021

\section{References}

1. Li K, Kong Y, Zhang M, Xie F, Liu P, Xu S. Differentiation of pluripotent stem cells for regenerative medicine. Biochem Biophys Res Commun. 2016;471(1): 1-4. https://doi.org/10.1016/j.bbrc.2016.01.182

2. Choi YJ, Park SK, Kang HI, Roh SH. Effects of exogenous insulin-like growth factor 2 on neural differentiation of Parthenogenetic murine embryonic stem cells. Reprod Dev Biol. 2012;36(1):33-7.

3. Chal J, Pourquié O. Making muscle: skeletal myogenesis in vivo and in vitro. Development. 2017;144(12):2104-22. https://doi.org/10.1242/dev.151035. 
4. Oh Y, Jang J. Directed differentiation of pluripotent stem cells by transcription factors. Mol Cell. 2019;42(3):200-9. https://doi.org/10.14348/ molcells.2019.2439.

5. Kodaka Y, Rabu G, Asakura A. Skeletal muscle cell induction from pluripotent stem cells. Stem Cells Int. 2017;2017:1-16. https://doi.org/10.11 55/2017/1376151.

6. Chal J, Al Tanoury Z, Hestin M, Gobert B, Aivio S, Hick A, et al. Generation of human muscle fibers and satellite-like cells from human pluripotent stem cells in vitro. Nat Protoc. 2016;11(10):1833-50. https://doi.org/10.1038/ nprot.2016.110.

7. Chal J, Oginuma M, Al Tanoury Z, Gobert B, Sumara O, Hick A, et al. Differentiation of pluripotent stem cells to muscle fiber to model Duchenne muscular dystrophy. Nat Biotechnol. 2015;33(9):962-9. https://doi.org/10.103 8/nbt.3297.

8. Bar-Nur O, Gerli MF, Di Stefano B, Almada AE, Galvin A, Coffey A, et al. Direct reprogramming of mouse fibroblasts into functional skeletal muscle progenitors. Stem Cell Rep. 2018;10(5):1505-21. https://doi.org/10.1016/j. stemcr.2018.04.009.

9. Davis $\mathrm{RL}$, Weintraub $\mathrm{H}$, Lassar AB. Expression of a single transfected CDNA converts fibroblasts to myoblasts. Cell. 1987;51(6):987-1000. https://doi.org/1 0.1016/0092-8674(87)90585-X

10. Berkes CA, Tapscott SJ. MyoD and the transcriptional control of myogenesis. Semin Cell Dev Biol. 2005;16(4-5):585-95. https://doi.org/10.1016/j.semcdb.2 005.07.006.

11. Hernández-Hernández O, Ávila-Avilés RD, Hernández-Hernández JM. Chromatin landscape during skeletal muscle differentiation. Front Genet 2020;11:1136.

12. Charge SB, Rudnicki MA. Cellular and molecular regulation of muscle regeneration. Physiol Rev. 2004;84(1):209-38. https://doi.org/10.1152/ physrev.00019.2003.

13. Jiwlawat $N$, Lynch E, Jeffrey J, Van Dyke JM, Suzuki M. Current progress and challenges for skeletal muscle differentiation from human pluripotent stem cells using transgene-free approaches. Stem Cells Int. 2018;2018:1-18. https://doi.org/10.1155/2018/6241681

14. Nakajima T, Shibata M, Nishio M, Nagata S, Alev C, Sakurai H, et al. Modeling human somite development and fibrodysplasia ossificans progressiva with induced pluripotent stem cells. Development. 2018;145:16.

15. Chen $A E$, Ginty DD, Fan C-M. Protein kinase a signalling via CREB controls myogenesis induced by Wnt proteins. Nature. 2005;433(7023):317-22. https://doi.org/10.1038/nature03126.

16. Xu C, Tabebordbar M, lovino S, Ciarlo C, Liu J, Castiglioni A, et al. A zebrafish embryo culture system defines factors that promote vertebrate myogenesis across species. Cell. 2013;155(4):909-21. https://doi.org/10.1016/j.cell.2013.10. 023.

17. Genovese NJ, Domeier TL, Telugu BPV, Roberts RM. Enhanced development of skeletal myotubes from porcine induced pluripotent stem cells. Sci Rep. 2017;7(1):41833. https://doi.org/10.1038/srep41833.

18. Ding S, Wang F, Liu Y, Li S, Zhou G, Hu P. Characterization and isolation of highly purified porcine satellite cells. Cell Death Dis. 2017;3(1):1-11.

19. Olson EN. MyoD family: a paradigm for development? Genes Dev. 1990;4(9): 1454-61. https://doi.org/10.1101/gad.4.9.1454.

20. Choi KH, Yoon JW, Kim M, Jeong J, Ryu M, Park S, et al. Optimization of culture conditions for maintaining pig muscle stem cells in vitro. Food Sci Anim Resour. 2020;40(4):659-67. https://doi.org/10.5851/kosfa.2020.e39.

21. Choi KH, Park JK, Kim HS, Uh KJ, Son DC, Lee CK. Epigenetic changes of lentiviral transgenes in porcine stem cells derived from embryonic origin. PLoS One. 2013:8(8):e72184. https://doi.org/10.1371/journal.pone.0072184.

22. Choi KH, Park JK, Son D, Hwang JY, Lee DK, Ka H, et al. Reactivation of endogenous genes and epigenetic remodeling are barriers for generating transgene-free induced pluripotent stem cells in pig. PLoS One. 2016;11(6) e0158046. https://doi.org/10.1371/journal.pone.0158046.

23. Livak KJ, Schmittgen TD. Analysis of relative gene expression data using realtime quantitative $P C R$ and the 2- $\Delta \Delta C T$ method. Methods. 2001:25(4):402-8

24. Taylor SM, Jones PA. Changes in phenotypic expression in embryonic and adult cells treated with 5-azacytidine. J Cell Physiol. 1982;111(2):187-94. https://doi.org/10.1002/jcp.1041110210.

25. Weintraub H, Tapscott SJ, Davis RL, Thayer MJ, Adam MA, Lassar AB, et al. Activation of muscle-specific genes in pigment, nerve, fat, liver, and fibroblast cell lines by forced expression of MyoD. Proc Natl Acad Sci. 1989; 86(14):5434-8. https://doi.org/10.1073/pnas.86.14.5434.
26. Bichsel C, Neeld D, Hamazaki T, Chang $\sqcup$, Yang $\sqcup$, Terada N, Jin S. Direct reprogramming of fibroblasts to myocytes via bacterial injection of MyoD protein. Cell Rep. 2013;15(2):117-25. https://doi.org/10.1089/cell.2012.0058.

27. Kabadi AM, Thakore PI, Vockley CM, Ousterout DG, Gibson TM, Guilak F, et al. Enhanced MyoD-induced transdifferentiation to a myogenic lineage by fusion to a potent transactivation domain. ACS Synth Biol. 2015:4(6):68999. https://doi.org/10.1021/sb500322u.

28. Fong AP, Yao Z, Zhong JW, Johnson NM, Farr lii GH, Maves L, et al. Conversion of MyoD to a neurogenic factor: binding site specificity determines lineage. Cell Rep. 2015;10(12):1937-46. https://doi.org/10.1016/j. celrep.2015.02.055.

29. Davis RL, Cheng P-F, Lassar AB, Weintraub H. The MyoD DNA binding domain contains a recognition code for muscle-specific gene activation. Cell. 1990;60(5):733-46. https://doi.org/10.1016/0092-8674(90)90088-V.

30. Heidt AB, Rojas A, Harris IS, Black BL. Determinants of myogenic specificity within MyoD are required for noncanonical $E$ box binding. Mol Cell Biol. 2007:27(16):5910-20. https://doi.org/10.1128/MCB.01700-06.

31. Huang J, Weintraub $H$, Kedes $L$. Intramolecular regulation of MyoD activation domain conformation and function. Mol Cell Biol. 1998;18(9): 5478-84. https://doi.org/10.1128/MCB.18.9.5478.

32. Xie $X, F u$ Y, Liu J. Chemical reprogramming and transdifferentiation. Curr Opin Genet Dev. 2017;46:104-13. https://doi.org/10.1016/j.gde.2017.07.003.

33. Tanaka A, Woltjen K, Miyake $K$, Hotta A, Ikeya M, Yamamoto T, et al. Efficient and reproducible myogenic differentiation from human iPS cells: prospects for modeling Miyoshi myopathy in vitro. PLoS One. 2013;8(4):e61540. https://doi.org/10.1371/journal.pone.0061540.

34. Conerly ML, Yao Z, Zhong JW, Groudine M, Tapscott SJ. Distinct activities of Myf5 and MyoD indicate separate roles in skeletal muscle lineage specification and differentiation. Dev Cell. 2016;36(4):375-85. https://doi. org/10.1016/j.devcel.2016.01.021.

35. Jiwlawat S, Lynch E, Glaser J, Smit-Oistad I, Jeffrey J, Van Dyke JM, et al. Differentiation and sarcomere formation in skeletal myocytes directly prepared from human induced pluripotent stem cells using a sphere-based culture. Differentiation. 2017;96:70-81. https://doi.org/10.1016/j.diff.2017.07.004.

36. Lassar $A B$, Paterson BM, Weintraub $H$. Transfection of a DNA locus that mediates the conversion of 10T12 fibroblasts to myoblasts. Cell. 1986:47(5): 649-56. https://doi.org/10.1016/0092-8674(86)90507-6.

37. Stresemann C, Lyko F. Modes of action of the DNA methyltransferase inhibitors azacytidine and decitabine. Int J Cancer. 2008;123(1):8-13. https:// doi.org/10.1002/ijc.23607.

38. Taylor SM, Jones PA. Multiple new phenotypes induced in 10T12 and 3T3 cells treated with 5-azacytidine. Cell. 1979;17(4):771-9. https://doi.org/10.101 6/0092-8674(79)90317-9.

39. Kiziltepe T, Hideshima T, Catley L, Raje N, Yasui H, Shiraishi N, et al. 5Azacytidine, a DNA methyltransferase inhibitor, induces ATR-mediated DNA double-strand break responses, apoptosis, and synergistic cytotoxicity with doxorubicin and bortezomib against multiple myeloma cells. Mol Cancer Ther. 2007;6(6):1718-27. https://doi.org/10.1158/1535-7163.MCT-07-0010.

40. Ito N, Kii I, Shimizu N, Tanaka H, Si T. Direct reprogramming of fibroblasts into skeletal muscle progenitor cells by transcription factors enriched in undifferentiated subpopulation of satellite cells. Sci Rep. 2017;7(1):1-12.

41. Capra JA, Singh M. Predicting functionally important residues from sequence conservation. Bioinformatics. 2007;23(15):1875-82. https://doi. org/10.1093/bioinformatics/btm270.

42. Tapscott SJ. The circuitry of a master switch: Myod and the regulation of skeletal muscle gene transcription. Development. 2005;132(12):2685-95. https://doi.org/10.1242/dev.01874.

43. Brennan TJ, Chakraborty T, Olson EN. Mutagenesis of the myogenin basic region identifies an ancient protein motif critical for activation of myogenesis. Proc Natl Acad Sci. 1991;88(13):5675-9. https://doi.org/10.1073/ pnas.88.13.5675.

44. Hernández-Hernández JM, García-González EG, Brun CE, Rudnicki MA. The myogenic regulatory factors, determinants of muscle development, cell identity and regeneration. Semin Cell Dev Biol. 2017;72:10-8. https://doi. org/10.1016/j.semcdb.2017.11.010.

45. Kim B, Ko NY, Hwang SS, Kim DH, Park JK, Ryoo ZY, et al. Growth factors supplementation in culture medium leads to active proliferation of porcine fibroblasts. Reprod Dev Biol. 2011;35(3):301-6.

46. Kimura E, Han JJ, Li S, Fall B, Ra J, Haraguchi M, et al. Cell-lineage regulated myogenesis for dystrophin replacement: a novel therapeutic approach for 
treatment of muscular dystrophy. Hum Mol Genet. 2008;17(16):2507-17. https://doi.org/10.1093/hmg/ddn151.

47. Lattanzi L, Salvatori G, Coletta M, Sonnino C, De Angelis MC, Gioglio L, et al. High efficiency myogenic conversion of human fibroblasts by adenoviral vector-mediated MyoD gene transfer. An alternative strategy for ex vivo gene therapy of primary myopathies. J Clin Invest. 1998;101(10):2119-28. https://doi.org/10.1172/JCl1505.

48. Tomczak KK, Marinescu VD, Ramoni MF, Sanoudou D, Montanaro F, Han M, et al. Expression profiling and identification of novel genes involved in myogenic differentiation. FASEB J. 2004;18(2):1-23. https://doi.org/10.1096/fj. 03-0568fje.

49. Gianakopoulos PJ, Mehta V, Voronova A, Cao Y, Yao Z, Coutu J, et al. MyoD directly up-regulates premyogenic mesoderm factors during induction of skeletal myogenesis in stem cells. J Biol Chem. 2011;286(4):2517-25. https:// doi.org/10.1074/jbc.M110.163709.

50. Cao Y, Yao Z, Sarkar D, Lawrence M, Sanchez GJ, Parker MH, et al. Genomewide MyoD binding in skeletal muscle cells: a potential for broad cellular reprogramming. Dev Cell. 2010;18(4):662-74. https://doi.org/10.1016/j. devcel.2010.02.014

51. Weiss A, McDonough D, Wertman B, Acakpo-Satchivi L, Montgomery K, Kucherlapati R, et al. Organization of human and mouse skeletal myosin heavy chain gene clusters is highly conserved. Proc Natl Acad Sci. 1999; 96(6):2958-63. https://doi.org/10.1073/pnas.96.6.2958.

52. Choi K-H, Lee C-K. Pig pluripotent stem cells as a candidate for biomedical application. J Anim Reprod Biotechnol. 2019;34(3):139-47. https://doi.org/1 0.12750/JARB.34.3.139.

53. Ezashi T, Yuan Y, Roberts RM. Pluripotent stem cells from domesticated mammals. Ann Rev Anim Biosci. 2016;4(1):223-53. https://doi.org/10.1146/a nnurev-animal-021815-111202.

Ready to submit your research? Choose BMC and benefit from:

- fast, convenient online submission

- thorough peer review by experienced researchers in your field

- rapid publication on acceptance

- support for research data, including large and complex data types

- gold Open Access which fosters wider collaboration and increased citations

- maximum visibility for your research: over $100 \mathrm{M}$ website views per year

At BMC, research is always in progress.

Learn more biomedcentral.com/submissions 